\title{
Piety in Traditional Culture and Its Aspects in Vietnam Today*
}

\author{
Assoc. Prof., Dr. Nguyen Thi Tho
}

Hanoi National University of Education, Vietnam; Email: thodhsp@gmail.com

\author{
Dr. Hoang Thi Hanh
}

Hanoi University of Science and Technology, Vietnam

\section{Doi:10.5901/mjss.2016.v7n2s1p98}

\section{Abstract}

This essay presents the filial piety in Vietnamese traditional culture and its new presentation in modern life. The positive aspect, new phenomenon occurred such as: Building society-sponsor centers for alone elderly who has none to depend on, Hiring maid to take care parents and grandparents, Changing from traditional family model (grand) to nuclear family model (little). Such phenomenon positively effect to the filial piety and the elderly are looked after better. However, various negative phenomena occurred such as: Excessively holding longevity wishing ceremony for old parents and grandparents, Exccessively ancestor-worship leading to waste money, Building tombs I unorganized way. In general, the filial piety in Vietnam is changing depend on the economic-social life that matches with the principle of Marxist-Leninist philosophy: "Social existence decides social consciousness".

Keywords: filial piety, traditional culture, Vietnam

\section{Introduction}

Piety is one of the traditional values of Vietnamese people. Such value has been existing in the agricultural- rural society for thousands of historical years. However, in several recent decades, when the globalization wave has entered the country, together with two-faced impacts of socialist-oriented market economy, the Piety has faced a number of huge challenges and it has been in risk of disguise. The connotation of this concept has not been as before anymore but changed. The expression of Piety has also been featured modernly.

This article is intended to present the Piety in the traditional culture and its new aspects in Vietnam currently; thereby, it proves Marx's treatise: It is the material essence of things that the social awareness does not determine the social existence but the social existence determines the social awareness because "mankind must first of all eat, drink, have shelter and clothing, before it can pursue politics, science, art, religion, philosophy" (Marx and F. Engels, 1995, vol. $19, p .166)$. It means that the change in social existence will lead to the change in social awareness; in other words, the material things determine the spiritual things, in which the moral factor plays the important role in determining the humanity as well as the preeminence of a social regime.

\section{Research Methodology}

In order to write this essay, author applies many philosophical and sociological methods like: unity logic and history, analysis and summarize, collective and comparative, synchronic and diachronic methods.

\section{Content}

\subsection{Piety in traditional culture}

According to Confucianism, "Piety" is a basic ethical category belonging to "Tam cương (Three moral bonds)" - three human relationships - they are "Trung" (ruler - ruled), Hiếu (parents - children), Tiết (husband - wife) initiated by Dong Zhongshu in Han dynasty. The main content of piety is: children must respect and obey their parents with the principle "father orders son to die, it is filial impiety if the son fails to obey the order" and when the children get married "wherever the parents want their children to sit, the children will sit there". Children must serve and take care of their 
parents when they are old or sick and must organize funeral, worship their parents when they passed away.

"Filial piety" of Vietnamese people was developed from the days of nation establishment with the story that Lac Long Quan married to Au Co and "gave birth to our people in a sac containing eggs" (Nguyen Khoa Diem). One hundred children were born, half of them went to the mountainous region, plough virgin land for cultivation and other half went to the seawards, opened the dynasties of Hung King that we today we have a date of Death Anniversary of the Hung Kings with the line of poetry every Vietnamese person knows by heart: "Anywhere we go, we must remember the 10th of March".

In this National holiday, according to regulations of the National Assembly of Vietnam (since 2007), civil staff nationwide will be off work to remember their original point, commemorate and pay tribute to the contribution of Hung Kings who are the founders of the nation. For recognizing the human nature of this National Day in commemoration of their ancestors, in 2013, UNESCO recognized "The Hung Kings Worship Ritual" as an "Masterpieces of the Oral and Intangible Heritage of Humanity". This is a festival full of national identity and character which can not be seen in other place of the world. The festival of Hung King Worship Ritual is an occasion converging the spirit of national solidarity Vietnam nation, which has been created from 54 ethnic groups of people. The national spiritual character is the converging point of the strength to become a powerful wave plunging foreign aggressors and invaders, defending and protecting the country's border areas.

From "National piety", we return to "Family piety". In folklore, especially in folk-songs - a type of anonymous literature or by word of mouth, we can easily find many folk-songs praising the boundless credit of the parents and gratitude of children for their parents: "The merit of father is like a tall mountain, and the care by mother is like an endless spring, children' filial piety is to attend to their aged parents with all heart" (Vu Ngoc Phan, 1998, p.447).

Taishan is a mountain which have supernatural power in China located in Shandong province northern of Taishan wall covering an area of $426 \mathrm{~km}^{2}$. The ancients called this mountain as Thiên trụ (sky-pillar). This was also considered the holy land of Taoism and the place of performing rituals of the Emperor dynasties of China, therefore, there are many valuable cultural heritages for recognizing the contributions by many generations. Taishan has been connected to natural and spiritual phenomena such as dawn of a day, generation and regeneration of a human life. From a true mountain, by means of abstraction, Vietnamese people use Taishan as a symbol for the father's merit to give birth and foster his children. Together with the father's great merit is the infinite goodness and love as "water from the endless spring" of the mother. It seems to be not enough to use a specific mountain, source of water for comparing with the merit and goodness of parents, the Vietnamese ancients used comparison method of higher level, more abstract that is "sky and sea" - the two wide categories including all things and all beings and species as specified in the saying "Water running to wherever runs to the sea, moon setting wherever can not set outside the sky"; "Father's merit is as sky / Mother's goodness is as water in Eastern see / High mountain and immense sea/ Children must have filial piety"; "High mountain is not higher parents' merit and goodness". "The best way of cultivating virtue and morals is respect and love parents " (Vu Ngoc Phan, 1998, p.451).

"Chín chữ cù lao" (nine hard works) mentioned here by folk poetry became the language symbol recognizing nine merits of the parents from giving birth to the date when children grow up and mature: "Sinh (give birth) - Cúc (foster) Phủ (comfort) - Súc (breast feed) - Trường (feed) - Dục (educate) - Cố (take care) - Phục (educate based on children's personality) - Phúc (protect)". Nine hard works are maintained by parents all their life, therefore, when parents passed away, children must be responsible for worshiping them in compliance with the Vietnamese fundamental moral code of ancestors worship: "Parents' merit and goodness are immense/Worship parents with all heart " (Vu Ngoc Phan, 1998, p.452).

Only such sentences in treasure of Vietnamese proverbs, folk poems and folk songs prove the "Piety" of Vietnamese people- a traditional moral philosophy which engraves in the mind of each citizen. The "Piety" likes glue which connects closely maternal love, family, community, fatherland and country. The citizens in other countries rarely call each other "compatriot"; their children call their parents beloved names which characterize regional language. Such beloved calls have become popular in everyday language of the citizens from the lowland to upland, creating a close-knit spirit among ethnics groups in Vietnamese Nation- State.

"Piety" in Vietnamese culture is not a common moral and abstract category but becomes the moral principles and human behavior, particularly in families under the model of "three-generation coresidence" or "four-generation coresidence". In the cramped but snug space, the descendants thoroughly care for their parents, grandparents and greatgrandparents. There, the generations which are blood relations respect, protect and help mutually under the principle "blood is thicker than water". To commend the model of families which create harmonious relationship among family members of many generations, in feudal dynasty, King often applied the regime of reward; nowadays; annually, competent authorities issue certificate of "Cultural Family". 
From the past to now, we see that the Piety in Vietnam currently has changed in many different directions. So, which direction is the Piety in Vietnam currently happening? What are the new aspects of the Piety currently?

\subsection{New aspects of Piety in Vietnam currently}

Currently, in Vietnam, under the impact of the socialist-oriented market economy and the process of exchange and integration, the Piety has not only changed its connotation but its expression as well. Hereunder, we shall analyze several new expressions of Piety in daily life.

\subsubsection{Positive aspect}

Under the positive impact of the market economy and the process of exchange and integration, the implementation of Piety has changed. In addition to traditional contents and implementation ways of Piety, regarding social aspect, some new social services have been established, such as: Elderly caring and sponsoring center; home-helpers hired by some families that are in good financial conditions to care for their parents at home.

Firstly, the establishment of homeless elderly caring and sponsoring center has expressed the preeminence of the society towards the elderly. In the center, the old people without children or relatives are gathered from the neighboring regions to be regularly fostered and cared in all aspects, from nutrition to healthcare. Initially, the center has been established only for the lonely and homeless elderly; then, intentionally or unintentionally, it has become the common house so that those who demand to "send their parents" in shall have conditions, particularly time, to do well their jobs; then they shall visit their parents in such center. This is also a good thing which reflexes a new express of the Piety. In the centers, the old people shall be cared thoughtfully in all aspects. They shall be satisfied with the public communication, conversation, updating information via mass media. Even many of them have feelings with each other and share the joy as well as sadness of the age.

Secondly, some families that are in good financial conditions but lack of time to care for their parents or they do not want to do that; as a result, they hire home-helpers to care for their parents in both daily activities (eat, drink, personal hygiene, healthcare) and spiritual life such as reading books, exchanging confidences, information, walking outside, etc... The appearance of such "caring" service is a joyful signal of the Piety because parents are regularly and thoughtfully cared. The regular presence of home-helpers avoids sudden incidents. Actually, this service is established on the principle: "Honors change manners" by the families that are in good financial conditions; on the contrary, the poor families have still cared for their parents in their own ways. Moreover, this service has offered jobs to a huge workforce in the society, decreasing the pressure on unemployment.

Regarding family aspect, scope is changed from expanded family into nuclear family; the democracy in the family is more heightened; children may live separately from their parents but still care for them in weekends or Tet holiday. Many festivals have been recovered and well affected the Piety, such as Ullambala Festival... Traditionally, according to Confucianism which heightens absolutely the parental role, the children must live under the principle that, when they are little aged, "if a child is condemned to death by his father, he cannot live without becoming impious"; when they grow up and get married, "where the parents place you, there you must sit". In the folklore, almost everyone knows by heart the following precepts which concern the duties of children toward their parents: "An unsalted fish is soon rotten, so the disobedient child will be spoiled"; nowadays, in the modern life, under the impact of economic conditions and cultural exchange, the children have the freedom of selecting their occupation and deciding their destiny.

Prof., Dr. Ho Ngoc Dai, an educational psychologist, in book "Bài báo" (See: Ho Ngoc Dai, 2000), with series of articles ("Parent-child relationship", "Dare to be impertinent", "Children have the right to be wrong", "What is impertinence") proves and analyzes that the parent- child relationship in the modern society is the bilateral and equal relationship. Parents bring up and educate their children when they are small. When the children grow up, they are obligatory to care for their parents. It is summarized in: "Save for a rainy day" or "raising children serves the purpose of preparing for one's old age". Actually, this concept was mentioned traditionally. For example, "Fear of father at young age, fear of children at old age". "Fear" herein has many meanings, including the obedience and compliance with mutual ideas. By vivid examples, he thinks that, in the modern society, "an unsalted fish is soon rotten" is not completely true because, actually, "an unsalted fish is not rotten" by putting such fish in refrigerator. It's just joking. Such explanation implies that nowadays, the children have opportunities to learn and travel much, so they may acquire more knowledge in many fields than their parents. Thus, they may select the potential optimal measures for their life under the principle: "The younger generations are to be feared, the younger generations know better". In the modern society, the young have the freedom of marriage on the basis of inquiring information of "life partner", then "informing" their parents for mutual 
approval and decision of wedding party.

Therefore, we can see that, in current conditions, the implementation of Piety has changed positively against the previous time in order to conform to the development of modern society. However, in other viewpoint, the negative impacts are available.

\subsubsection{Negative aspects}

Firstly, in the aspect that descendants care for grandparents and parents:

Currently, in order to show the filial piety, "Longevity wishing ceremony" towards parents has developed strongly. The descendants hold the longevity wishing ceremony when their parents or grandparents are "Seventy years old", "Eighty years old", "Ninety years old", or "One hundred years old". Initially, the longevity wishing ceremony has only been taken place in the families that have good financial conditions; but "the cocks rival each other for crowing" (which means "I must have better thing than you have (or at least the same"), the movement has been spread around, even to the poor families. Such longevity wishing ceremonies must be held carefully to avoid "complaints and blames". As a result, such ceremonies have initially held by several banquets to invite relatives; then the number of banquets has reached tens, even hundreds. The ceremonies have been taken place for several continual days. "Splash water after the rain" (which means "taking advantage of the situation to make benefit"), like funeral or wedding party, the descendants who have power and authority take advantage of the longevity wishing ceremonies to benefit; and unintentionally, a phenomena which has been initially meaningful has become a social civil, disturbing the public opinion and damaging parents' reputation.

Our parents nowadays have learned carefully, obtaining qualified degrees, controlling many scientific fields, reading many books, studying philosophy and well understanding dialectics, particularly cause and effect relationship. Therefore, they are aware that if they treat well their parents (i.e., grandparents), they will be an example to their children. On this occasion, we would like to tell a fable related to this issue: A couple, because of difficult conditions and many children, could not nourish their old parents. In a night, they discussed with each other to weave a basket, telling their parents to sit inside the basket, carrying them to a forest and "starving" them. When they carried the basket for a distance, suddenly, their oldest son said: "You remember to bring the basket back for me to use later". They understood that their oldest son listened to their discussion and gave them an "expensive" advice on the basis of cause and effect theory. They stopped and then, worked hard to nourish and care for their parents in order to be the example to their children. Therefore, herein, the modern Piety is interlaced by "Benefit" and calculating but not purely "fair-minded" as before.

Secondly, in the aspect that the descendants hold funeral ceremonies and worship parents, grandparents

In legends of funeral ceremonies and worship, we see that it was very tough-minded such as, going into mourning for parents in three years, building sepulchers, wearing melancholy faces and ragged clothes in the early weeks and month after parents' death. Nowadays, the situation has been changed. The descendants have not cried much in their parents' funerals; instead, they hired octet or other people to cry (hired crying) in the form of "pay your money and take your choice". It seems disappearance of feelings and spirit between the dead and the living.

The hiring of person to write funeral oration or loading funeral oration from Internet to read in the funeral has been developed. In addition, a phenomena which has currently sounded out the public opinion is that many people who have power, authority and wide social relationship have taken advantage of their parents' funeral to benefit. In the past, people who visited the funeral brought mainly fruits, flowers, confectionery, wine, tea, incense. Now, it seems $100 \%$ money, including "Vietnam dong" and "foreign currency". Whether the people in the world of the dead know the way to use such money or not?

The current worship has also changed much. Although the number of ceremonies has been decreased, a movement is arisen, that is to bring the soul of the dead to temples, sending photo for eternal worship at the temples. Actually, many "sacred temples" have been overloaded regarding service of "hired worship".

Worshipping objects have also been an issue which the discussion is required. The common people said "however the yang world; so is the yin world", which means that whatever the living need, the dead need the same and however the living lead their lives, the dead do the same. However, nowadays, the descendants do not mind such issue; they order the worshipping objects according to their hobby. They simply think that the first-class ceremony is, the more piety is. As a result, foreign filter-tipped cigarettes 555 , domestic alcohol, imported alcohol, first-class biscuit, imported fruits which are bought at supermarket... are placed on altar.

Similarly, using votive paper in worship and burning after ritual observation is much different from the past time. In the old time, votive paper is very simple such as clothes, hat, and essential personal things, with simple appearance 
copying from the reality, reasonable price. In the present time, with high technology, various materials, votive objects become very sophisticated and diversified, from clothes, hat to electronic equipments such as mobile phone, laptop, TV, fridge, motorbike, etc. and of course at "excessively high" price, requiring much cost from homeowners and causing environmental pollution due to their materials.

The worship nowadays doesn't follow a certain ritual; young people keep their hands clasped and "talk wild" without ceasing, while folklore says "đa vái, thất kinh", meaning that too much invocation (in wrong way) shows disrespecting.

"Tảo mộ" (cleaning and decorating the ancestral graves) by descendants on the grave visiting festival is modernized to become non-spiritual. People do it as their obligation or just because they are afraid of others laughing. The original meaning of word "tảo mộ" is sweeping away all litter, feral plants, re-banking, refreshing the graves after a year undergoing rain or sunshine, fog, wind. It is true in the past time, when graves are earthen embankment and face wild nature. However, today graves are "solidly concreted"; descendants just come to burn incense, no need to "do anything manually". The grave visiting festival is no longer an occasion for the whole society, each family or clan may arrange one day convenient for them to conduct it. Currently, the grave visiting festival commonly takes place on the days near by lunar New Year, when people are "in spare time", think about the past people and ask: "People from millennia past, where are your souls now?" Also, burying parents and relatives is modernized by the form of "cremation" then collecting ash, putting into cemetery, hiring cemetery keeper to burn incense on necessary days. It is quite convenient, but does the Piety in original meaning remain?

Not long after their parents are buried, the mausoleum was constructed. It can be said that recently the tombs building, especially in rural areas, typically in the central province of Thua Thien - Hue, has become an aggressively competing movement. A later-built tomb is always bigger, higher, and more epic than the previous one, requiring huge costs and making environmental pollution. Many homeowners without house for living people spend money to build a mausoleum. Therefore, cemetery is at risk of becoming street, with crowded tombs, small and big, high and low, facing north, east, south, etc. (subject to feng shui applicable to homeowner). In addition, if the dominance of cement against field and tomb construction is continued, will people in several hundred years have land left for living and cultivating? Furthermore, the movement of building tombs for parents, an emerging problem, with the cost of up to several billion, even millions of US Dollars, rings an alarm bell. In our opinion, showing attitude to parents by building tombs as mentioned above need reorganizing in conformity with economic condition, culture and environment, rather than spontaneous action, causing bad influence on living environment of future generations. The large-scale tombs should be built for special people (great culturists, scientists, famous politicians, etc.) only; the rest (ordinary people) should be buried in old form to save land for the living people.

The mechanism of market economy has fundamentally changed the social relations, including ethical relationship, of which Piety is a nuclear. Like other types of relation, Piety is weighed and calculated profit and loss. In some large families with many children, taking care of parents is divided by month, year in a fair way for the children; even before the hand-over to the other child, parents are placed on the scale to determine who better treat their parents (based on weight). How can parents and descendants feel OK on seeing such adversity far different from tradition?

\section{Conclusion}

With the aforesaid examples, it can be seen that the expression of Piety nowadays differs a lot from the original. This difference is due to socio-economic condition; just the same as judgement by F. Engel in his work Anti - Duhring: "All moral theories have been hitherto the product, in the last analysis, of the economic conditions of society obtaining at the time" (Marx and F. Engels, 1994, vol. 20, p. 137). Piety, a phenomenon of ethical category, is not contrary to such law. New aspects of Piety being shown in Vietnam as mentioned earlier reflect a real society with powerful transformation of economic mechanism, from bureaucratic subsidized economy to socialist-oriented market economy.

In the era of market economy today, social life goes on with a fast rhythm, time is considered precious capital to generate wealth and enjoy the fruits of your own labor. In such context, the change of Piety in both content and form is natural to comply with the situation. However, we believe that the different expression in traditional and modern time can hardly change the nature of Piety in Vietnam; the national spirit and oriental character is still preserved. Piety in the modern time remains traditional features, reflecting the love of father-child, mother-child, and blood ties between members of the same family, clan. Despite its remarkable turn, Piety has and will accompany the nation in the endless journey to find the values of truthfulness, compassion, and beauty and affirm the national spirit as beautiful humanity and affection-respecting lifestyle cannot be lost even in circumstance of poverty. 


\section{Acknowledgement}

This research is funded by Vietnam National Foundation for Science and Technology Development (NAFOSTED) under grant number I1.7-2013.04

\section{References}

Cang, C.V. (2006). Filial piety and conduct in the past and present. National Cultural Publishing House.

Dai, Ho Ngoc (2000). "The article", Labour Publishing House.

Marx and F. Engels (1995). Collected Works. National Political Publishing House, vol. 19.

Marx and F. Engels (1994). Collected Works. National Political Publishing House, vol. 20.

Ho Chi Minh. (2000). Ho Chi Minh Volume. Vol. 7. National Political Publishing House.

Institute of Linguistics (2004). Vietnamese dictionary.

Kiet, D.P. (2006). Vietnamese Families - Traditional values and social mental - pathological issues.

Jamieson, N.L. (1993). Understanding Vietnam. Berkely: University of California press.

Lew, S.K. (1995). Filial piety and human society. Korea: The Academy of Korean Studies.

Nhan, N.T (Translation) (1999). Book of rites. Literature Publishing House.

Phan, Vu Ngoc (1998). Vietnamese proverbs, folk poems and folk songs, Social Science Publishing House.

Sang, T.L. (Chief - author). (2002). Literature in Chinese and Chinese- transcribed Vietnamese, vol. 1 - Four Books. Social Sciences Publishing House.

Tho, N.T. (2007). According to traditional filial duty, think about present filial duty. Review of Philosophy, No. 6, 2007.

Trai, N. (1952). Family instructions. (Corrected by Thi Nham Dinh Gia Thuyet). Tan Viet Book. 